\title{
EXPERIENCIAS ESCOLARES PARA A INFANCIA DESVALIDA - BRASIL IMPERIAL (1822-1889)
}

M. I. S. STAMATTO
$\begin{gathered}\text { Universidade Federal do Rio Grande do Norte } \\ \text { stamattoines@gmail.com }\end{gathered}$
Artigo submetido em junho/2016 e aceito em julho/2016
DOI: $10.15628 /$ holos.2016.4685

\section{RESUMO}

Abordam-se, neste texto, experiências escolares para a infância desvalida no Brasil Imperial. A partir do estabelecimento do Código Criminal em 1830, que fez parte do conjunto de leis que primeiramente organizaram a estrutura administrativa do Estado brasileiro, passou-se a tratar os indivíduos menores de 14 anos que não estavam sob os cuidados de suas famílias, em categorias distintas: órfãos, infratores, abandonados e desvalidos. Para as crianças desvalidas, aquelas em que a família atestasse pobreza, ou que tivessem sido criadas por instituições de caridade, foram instauradas dois tipos de estabelecimentos educacionais, de caráter profissionalizante, as Escolas de Educandos Artífices e as Companhias de Aprendizes Artífices, para a carreira militar. Essas escolas também podiam aceitar órfãos designados pelo Juiz de Órfãos. Porém, a maior parte dessas escolas existiu por períodos efêmeros. Aquela instalada na capital da província do Rio Grande do Norte, por exemplo, durou apenas quatro anos, de 1858 a 1862

PALAVRAS-CHAVE: Infância Desvalida, Brasil Império, Instituições Escolares

\section{SCHOOL EXPERIENCES OF DESTITUTE CHILDHOOD FROM THE IMPERIAL BRAZIL EPOCH (1822-1889)}

\begin{abstract}
This text approach school experiences of destitute childhood from the Imperial Brazil epoch. Since the establishment of the Criminal Code in 1830 - which was part of a set of laws that organized for the first time the administrative structure of the Brazilian State individuals less than 14 years old that were not in the care of their families started being treated in different categories: orphans, offenders, abandoned, and the 'destitute'. Destitute children were those whose family attested poverty or that had been raised by charity
\end{abstract}

institutions. For those children two kinds of educational establishments were created: the vocational focused 'Escolas de Educandos Artífices' and the military career focused 'Companhias de Aprendizes Artífices'. Those schools could also accept orphans designed by the Orphan Judge. However, most of those schools existed for short periods. The one installed on the capital of the Rio Grande do Norte province, for example, lasted only four years, from 1858 to 1862 .

KEYWORDS: Destitute Childhood, Imperial Brazil, Educational Establishments 


\section{INTRODUÇÃO}

Abordam-se, neste texto, experiências escolares para a infância desvalida no Brasil Imperial. Teve-se como objetivo sistematizar conceitos sobre a infância desvalida bem como realizar uma reflexão sobre as experiências escolares para as crianças consideradas desvalidas, no período de 1822-1889. Para a pesquisa trabalhou-se com a legislação de época referente ao tema como fonte histórica.

Com a independência oficializada em 1822, houve necessidade de estruturação do Estado brasileiro. Neste sentido a preocupação imediata foi com o estabelecimento da Assembleia Nacional Constituinte para a elaboração da primeira Constituição brasileira, que de fato foi outorgada em 1824. A partir dessa data, até aproximadamente 1834, passou-se a legislar as leis maiores da Nação, organizando e estabelecendo-se serviços, tais como o dos Correios e Telégrafos, o do Banco do Brasil, o do sistema jurídico, o da educação. Assim, o Código Criminal instituído em 1830, no qual se definia a etapa da infância, fez parte desse conjunto de leis que primeiramente organizaram a estrutura administrativa do Estado brasileiro.

\section{A INFÂNCIA DESVALIDA}

No século XIX, no Brasil, o que se considerava como infância variava de acordo a com legislação. Observando-se a jurisdição, antes de 1830, não havia diferença em relação a quem cometia o delito, entre o adulto e a criança. Poderia haver atenuantes ou a diminuição da pena, "era o sistema que compreendia o "jovem adulto", estando configurada a imputabilidade penal àqueles que ultrapassassem a barreira dos 21 anos" (GARCIA, 2011).

O Código Criminal brasileiro estabelecido em 1830 era explícito quanto à idade em que o indivíduo poderia ser punido: "Também não se julgarão criminosos: 10 Os menores de quatorze anos" (Art. 10). Este Código Criminal vigorou até 1890.

Portanto, em termos de responsabilidade civil, por esse Código Criminal, os indivíduos menores de 14 anos eram considerados inimputáveis, não podendo ser punidos por qualquer ato ilícito. Dessa forma, "a responsabilidade penal plena foi prevista para todos os indivíduos a partir dos 14 anos de idade, marco jurídico na passagem para a vida adulta" (SCHULER in: Vainfas, 2002, p. 378).

Entretanto, o mesmo Código permitia que os indivíduos menores de 14 anos que cometessem delitos, dependendo das circunstâncias, poderiam ser encaminhados às casas de correção. Isso significava que competia aos juízes criminais a avaliação do discernimento ou não do acusado, e por conseguinte, do seu status como criança ou adulto.

Já as leis que regulamentavam a educação no país recém independente, apresentaram distintas determinações sobre a idade para frequentar as escolas elementares, variando conforme a região. A primeira lei sobre o ensino primário de 15 de outubro de 1827, válida para todo o território nacional, referia-se a 'meninos' e 'meninas' não especificando qualquer idade. Já o Regulamento da Instrução Primária e Secundária da Corte de 1854 (Decreto no 1.331-A de 17 de fevereiro), estipulava como idade para a escola primária entre 5 e 14 anos e para a secundária entre 14 e 21 anos. 
Em geral no período imperial, determinava-se pela legislação escolar que somente as pessoas livres poderiam frequentar as escolas públicas. Também se excluía aqueles que sofressem de doenças contagiosas e os não vacinados.

A partir do estabelecimento do Código Criminal, passou-se a tratar os indivíduos menores de 14 anos que não estavam sob os cuidados de suas famílias, em categorias distintas: órfãos, infratores, abandonados e desvalidos. No vocabulário da época, desvaler significava "faltar com a proteção"; desvalido utilizado como adjetivo era alguém "desprotegido, desamparado" e como substantivo era o "pobre, desgraçado." Portanto, desvalimento correspondia a "falta ou perda de favor, de proteção, de valimento" (AULETE, 1881, p. 520). A diferença em relação a um abandonado, que também era alguém desprotegido e desamparado, era a condição familiar. $O$ desvalido era o indivíduo menor, desamparado, porque sua família não tinha condições sociais de fornecer-Ihe as condições necessárias à sua sobrevivência, era pobre. $\mathrm{O}$ abandonado não tinha família ou um adulto responsável por ele, por isso estava desamparado, estava na pobreza.

A criança desvalida seria aquela materialmente pobre, mas que contava com o apoio de alguém de sua família. Era um indivíduo cujos pais, por sua condição miserável, não podiam lhe dar aquilo que necessitava. Não eram consideradas infratoras, pois não haviam cometido nenhum crime contra a sociedade ou o Estado. Configuram-se enquanto crianças pobres, convivendo em meio à miséria e à ignorância, desprovidas de apoio, social, cultural e econômico. Não eram escravas, porém eram filhos de escravos "agraciados" pela Lei do Ventre Livre, de ex-escravos ou de homens brancos livres e pobres. Boa parte deles eram filhos de mães viúvas, ou abandonadas pelos maridos ou pela sorte. (LIMA, 2008, p. 29).

A criança abandonada "se configurava como aquela desprovida da assistência da família e do Estado, que ignorava e tratava como simples caso de polícia" (Lima, 2008, p. 29). Deveria ser encaminhada a instituições que a cuidassem, como asilos ou casas de assistência, pois não contava com nenhum adulto para dar-Ihe sustento. O Decreto no 1.133-A, por exemplo, estipulava:

Art. 62. Se em qualquer dos distritos vagarem menores de 12 anos em tal estado de pobreza que, além da falta de roupa decente para frequentarem as escolas, vivam em mendicidade, o Governo os fará recolher a uma das casas de asilo que devem ser criadas para este fim com um Regulamento especial.

Em quanto não forem estabelecidas estas casas, os meninos poderão ser entregues aos párocos ou coadjutores, ou mesmo aos professores dos distritos, com os quais o Inspetor Geral contratará, precedendo aprovação do Governo, o pagamento mensal da soma precisa para o suprimento dos mesmos meninos.

O indivíduo menor infrator "se referia à criança desprovida materialmente que havia cometido alguma infração, na maioria das vezes pequenos roubos ou furtos" (LIMA, 2008, p. 29), e neste caso, seria encaminhada a juízes criminais: "Se se provar que os menores de quatorze anos, que tiverem cometido crimes, obraram com discernimento, deverão ser recolhidos ás casas de correção, pelo tempo que ao Juiz parecer, com tanto que o recolhimento não exceda á idade de dezessete anos" (Código Criminal, Art. 13).

Aos órfãos era dado tratamento específico. As crianças de qualquer idade que tendo família haviam perdido o pai e a mãe, podiam pertencer a qualquer segmento social, ter ou não herança ficavam sob a responsabilidade do Juiz de Órfãos, autoridade judiciária que existia desde a época 
da colônia. Este cargo havia sido criado pelo rei de Portugal D. João V, nas vilas com mais de 400 moradores, entre os anos de 1709 e 1711. No período imperial, a função foi mantida e em 1832, foi estendida para cada comarca. "Cabia ao Juiz de órfãos encaminhar os expostos [recém-nascidos abandonados] para o recrutamento pelas tropas militares e para a aprendizagem de ofícios, além de cuidar de sua herança e outros interesses" (BOTELHO; REIS, 2008, p. 115).

De qualquer forma, qualquer que fosse a categoria em que estivessem enquadradas, havia crianças sem o acompanhamento de adultos, circulando nas ruas e espaços públicos das cidades e vilas do país. Estariam perambulando, mendigando, vendendo diversos produtos, trabalhando em pequenos serviços. Para Schuler, (2002, p. 377) as crianças de famílias pobres, livres ou libertas costumavam trabalhar desde os sete anos buscando a aprendizagem de um ofício ou um trabalho, o que significava entrar no mundo dos adultos já nessa idade.

Para as autoridades constituídas esta situação trazia problemas já que poderia acarretar desordens de todo o tipo, bem como proporcionar aos menores oportunidades de cometerem delitos e sofrerem violências. Além disso, os desocupados eram passíveis de punição pelo Código Criminal, considerado delito:

Não tomar qualquer pessoa uma ocupação honesta, e útil, de que passa subsistir, depois de advertido pelo Juiz de Paz, não tendo renda suficiente. (Art. 295).

Andar mendigando:

1 Nos lugares, em que existem estabelecimentos públicos para os mendigos, ou havendo pessoa, que se ofereça a sustenta-los.

20 Quando os que mendigarem estiverem em termos de trabalhar, ainda que nos lugares não hajam os ditos estabelecimentos. (Art. 296).

Além do que, para os segmentos sociais que estavam organizando o aparato estatal, faltava mão-de-obra para muitas atividades. Para as elites brasileiras no século XIX:

Uma sociedade sã, no sentido moral e físico, implicava o estabelecimento de uma população sem doenças, sem revoltas e sem crimes. Para isso, era necessário eliminar das ruas os vadios, os contagiosos e os degenerados. Antes de estimular a mendicância, era preciso evitar o seu desenvolvimento. Dar uma ocupação através do trabalho, tornando os indivíduos úteis para a sociedade, passava a ser uma preocupação do Estado brasileiro no século XIX. Estado que começava a desenvolver-se economicamente, precisando de homens bons, honestos e trabalhadores. (SILVA, W. 2011, p.2).

As escolas de primeiras letras, criadas "nos lugares mais populosos" e de acordo com as leis provinciais e da Corte não tiveram capacidade de alcançar todas as crianças em idade escolar, como atestam os inúmeros estudos sobre este período. Igualmente, não foram instituídas visando atingir as crianças que andavam soltas nas ruas. Em geral, as crianças que frequentavam as escolas públicas eram oriundas das redondezas, com famílias ou tutores designados pelos Juízes de Órfãos. 


\section{EXPERIÊNCIAS ESCOLARES PARA OS DESVALIDOS}

Para as crianças desvalidas, aquelas em que a família atestasse pobreza, ou que tivessem sido criadas por instituições de caridade, foram instauradas dois tipos de estabelecimentos educacionais, de caráter profissionalizante, as Escolas de Educandos Artífices e as Companhias de Aprendizes Artífices, para a carreira militar. Essas escolas também podiam aceitar órfãos designados pelo Juiz de Órfãos.

As Escolas de Artífices, igualmente denominadas de Colégios de Educandos Artífices ou Casas de Educandos Artífices, eram em regime de internato e desde o início foram destinadas ao ensino elementar e profissionalizante para os meninos. Rosilda Germano da Silva, ao estudar sobre - Colégio de Educandos Artífices fundado na província de Alagoas lembra que "o regime de internato, não era apenas a preparação para o trabalho que importava, era preciso à vigilância sobre as crianças, pois havia algo de "perigoso" nelas por isso o confinamento era indispensável" (SILVA, Rosilda, 2010, p. 29).

A primeira Casa de Educandos Artífices foi estabelecida na província do Pará em 1840 (Lei no 79 de 21 de outubro de 1840) e "deve ter funcionado como paradigma das demais" (CUNHA, 2005, p. 113) que foram criadas em todo o Império brasileiro a partir dessa data. Em 1841 foi instituída a do Maranhão e em 1847, a do Piauí. Na década seguinte foram criados os colégios de Alagoas em 1854, o do Ceará, Amazonas e Sergipe em 1856; o do Rio Grande do Norte em 1858 e o da Paraíba em 1859. Nos anos seguintes ainda foram fundadas mais duas dessas instituições em Goiás (1861) e em São Paulo (1874) (CUNHA, 2005, p. 113; LIMA, 2008, p. 42).

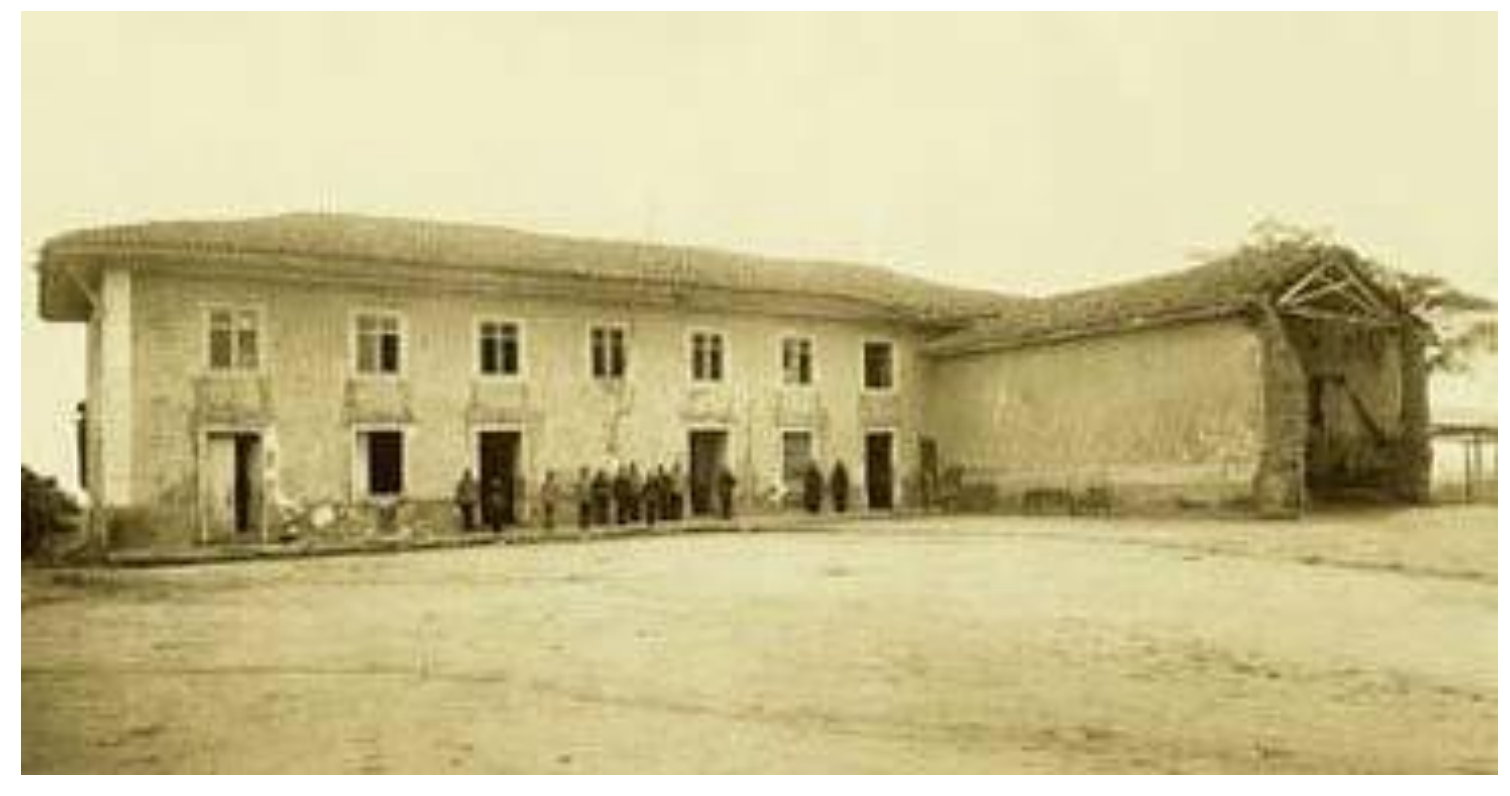

Experiências Escolares Para Meninos Desvalidos ${ }^{1}$

Fonte: Autor desconhecido - UOL Foto Blog: Saudade de Sampa.

www.saudadesampa.nafoto.net/photo20061103022935.html (Acesso: 16/03/2012), In: SILVA, Robson, 2015. p.207.

\footnotetext{
${ }^{1}$ Fotografia da sede da Fazenda Santana de 1915, onde funcionou entre os anos de 1825 e 1868 o Seminário de Santana. Em 1874 foi transformado em Instituto dos Educandos Artífices (São Paulo).
} 
Ensinavam-se, nessas casas, as primeiras letras, escultura, desenho, aritmética, noções gerais de álgebra, geometria e mecânica aplicada às artes e formava-se para os ofícios de alfaiate, músico, carpinteiro, marceneiro, pedreiro, ferreiro, serralheiro, canteiro, funileiro, espingardeiro, tanoeiro, caldeireiro, maquinista e sapateiro (CUNHA, 2005, p. 113-114).

A segunda forma de experiência escolar para as crianças pobres e desvalidas foram as Companhias de Aprendizes Artífices ou Companhias de Aprendizes Marinheiros oriundas do período anterior, no Brasil. Essas instituições profissionalizantes foram estabelecidas por Alvará Régio de D. Maria I de 1764. “Em 1799, à época de D. João, foram transformados em Companhias de Aprendizes do Arsenal de Guerra, voltados à instrução elementar e à aprendizagem de ofícios como marceneiros, tanoeiros, entre outros" (BOTELHO; REIS, 2008, p.52). Dessa forma, a prática de enviar meninos desvalidos e órfãos para as oficinas da Marinha já havia sido instituída no Brasil desde o período colonial.

Ao que parece essas Companhias continuaram existindo em funcionamento mesmo a partir do processo de independência brasileiro. Luiz Antônio Cunha apresenta o Arsenal de Guerra do Rio de Janeiro "com duzentos jovens praticando os mais diversos ofícios", em 1834, tendo sido admitidos por "regulamento baixado por decreto de 21 de fevereiro de 1832" (2005, p. 110). Indica também a existência de outros Arsenais, em 1836, no Pará, Pernambuco, Bahia, Mato Grosso e Rio Grande do Sul, todos "com menores aprendendo ofícios artesanais e manufatureiros" (CUNHA, 2005, p. 110).

Eram estabelecimentos militares, instituídos em diversos locais, no país, e que foram reorganizados nos anos de 1840, pela Lei n. 243 de 30 de Novembro de 1841 (artigo 39) e o Regulamento n. 113 - de 3 de Janeiro de 1842. Visavam explicitamente o ensino e a preparação profissional dos meninos pobres e desvalidos, acima dos sete anos, muitos deles oriundos da Roda de Expostos:

\footnotetext{
Nenhum menor poderá ser alistado nas sobreditas Companhias antes de oito anos de idade, nem depois que houver completado doze (Art. $2 \stackrel{\circ}{\circ}$ ).

Só podem ser admitidos nas mesmas Companhias:

1응 Os expostos.

2 Os órfãos indigentes.

3ㅇ Os menores, que viverem abandonados sem superior que vele na sua educação.

4ㅇ Os filhos de pais, que, por sua pobreza, não tiverem meios de os alimentar e educar (Art. 3ㅇ).
}

As crianças, chamadas de Aprendizes Menores, eram obrigadas a frequentar a escola de primeiras letras até saberem ler e escrever, e as quatro operações de aritmética. Nas horas vagas deveriam aprender nas diversas oficinas trabalhos próprios a sua capacidade (Art. 9ㅇ).

Ainda, as Instruções para execução, do Regulamento n. 113 de 3 de Janeiro de 1842, determinava cuidados para que os menores andassem sempre limpos, e decentemente vestidos, 
assistidos á mesa, e acompanhados sempre que se achassem reunidos, "e muito principalmente quando saírem em Corpo para fora do Arsenal" (Art. 12).

Os Aprendizes Menores precisavam, igualmente, estar em condições de saúde para serem aceitos e permanecerem matriculados na instituição:

Outro critério para admissão dos menores era sua aptidão para o trabalho, por isso a partir de 1857, a robustez física passou a ser condição para permanência na Companhia de Aprendizes. Aviso do Ministério da Guerra determinou inspeção de saúde nos meses de janeiro e julho, com o objetivo de desligar os menores quando se julguem incuráveis. (CRUDO, 1999, p.128 apud TAMURA, 2013, p.7).

A determinação do Ministério da Guerra foi observada, como Matilde Araki Crudo demonstra com vários casos sobre a Companhia de aprendizes em Mato Grosso, entre eles:

Em maio de 1866, o diretor do Arsenal de Guerra concorda com a exclusão menor Antônio Ferreira (admitido a 9/08/59) julgado por mais de uma vez sofrer de moléstia incurável (...). Apesar da mãe não ter meios de pagar à Fazenda Nacional a importância da criação de seu filho, o diretor acha que é uma boa aquisição aos cofres públicos dispensá-lo para não continuar semelhante dispêndio sem o menor proveito. (CRUDO, 2000, p.11).

Com a fundação da primeira Companhia de Aprendizes Marinheiro do Brasil (decreto de $\mathrm{n}^{\circ}$ 14 de 1840), sediada na Corte, foram criadas gradativamente mais 17 escolas de preparação de marinheiros em diversas províncias do país: Pará (Decreto № 1517 de 4 de janeiro de 1855); Bahia (Decreto no 1543 de 27 de janeiro de 1855); Mato Grosso (Decreto № 1987 de 7 de outubro de 1857); Pernambuco (Decreto no 2003 de 24 de outubro de 1857); Santa Catarina (Decreto no 2003 de 24 de outubro de 1857); Maranhão (Decreto no 2725 de 12 de janeiro de 1861); Rio Grande do Sul (Decreto no 2725 de 12 de janeiro de 1861); Espírito Santo (Decreto no 2890 de 8 de fevereiro de 1862); Paraná (Decreto no 3347 de 26 de novembro de 1864); Ceará (Decreto no 3347 de 26 de novembro de 1864); Sergipe (Decreto no 4112 de 29 de fevereiro de1868); Santos (Decreto no 4112 de 29 de fevereiro de 1868); Parayba do Norte (Decreto no 4680 de 17 de janeiro de 1871); Amazonas (Decreto no 4680 de 17 de janeiro de 1871); Rio Grande do Norte (Decreto no 5181 de 16 de dezembro de 1872); Piauy (Decreto no 5309 de 18 de junho de 1873); e Alagoas (Decreto no 5847 de 2 de janeiro de 1875) (SILVA, W. 2011, p.7).

Para as meninas desvalidas, que não podiam frequentar nem os Colégios de Educandos Artífices, nem as Companhias de Aprendizes da Marinha, havia os asilos e casas de assistência esparsamente existentes no país. Foram fundados também Educandários femininos geralmente ligados a alguma ordem religiosa em que se ensinavam às meninas o ensino elementar, de acordo com sua condição social, e as preparavam seja para a vida religiosa, seja para o casamento. Além disso, restava a escola de primeiras letras pública, onde podiam aprender 'as prendas domésticas', para posteriormente poderem sustentar-se como costureiras, bordadeiras, cozinheiras, entre outras atividades 'da casa'. 


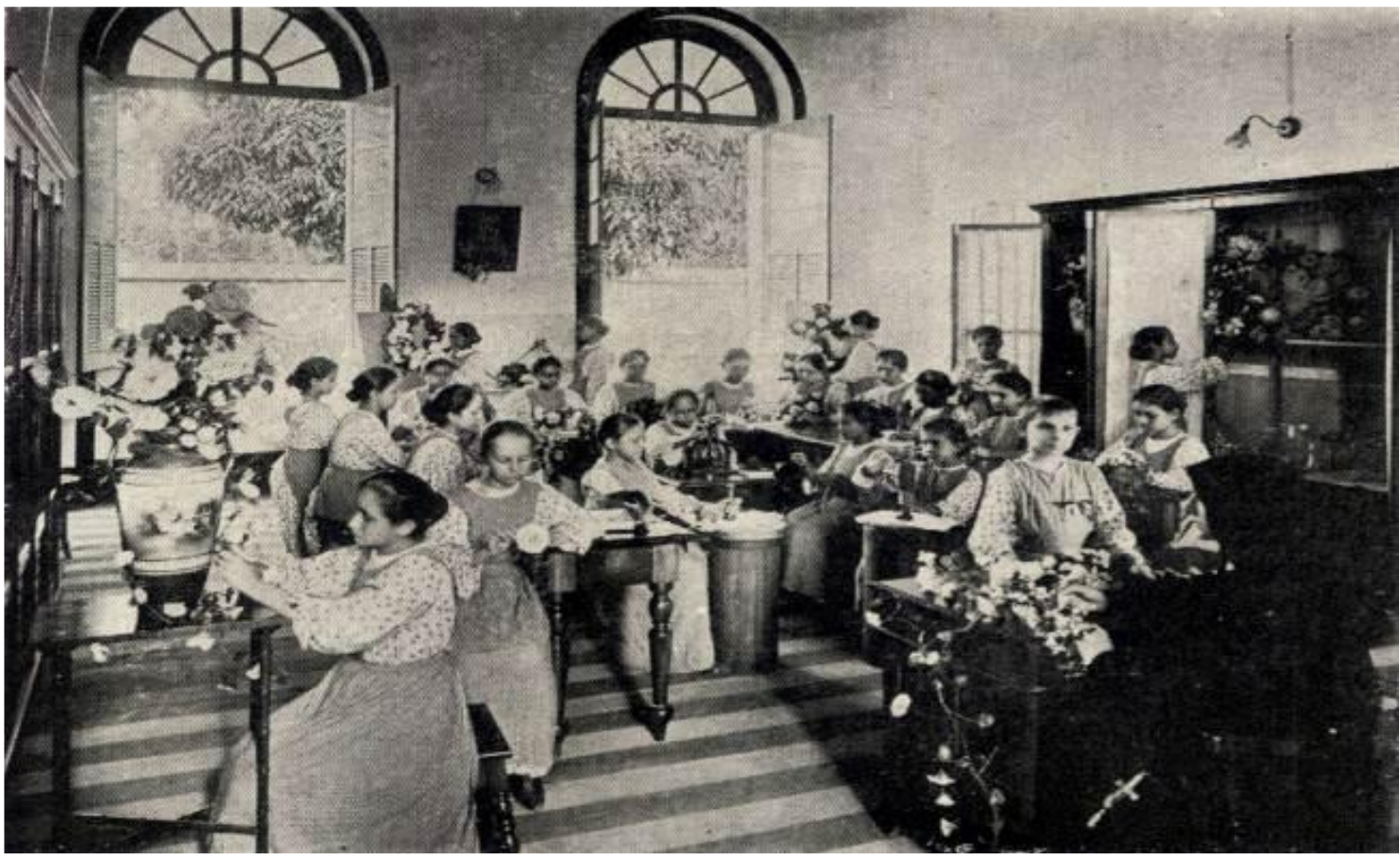

Experiências Escolares Para Meninas Desvalidas²

Fonte: SABINO, Eliane, 2012, capa.

Com a Guerra do Paraguai e a promulgação da Lei do Ventre Livre, de 28 de setembro de 1871, o contingente de órfãos e crianças desvalidas no Brasil iria aumentar ainda mais, inclusive com a inserção nesse grupo dos ingênuos, filhos de escravas nascidos depois desta lei. Isso faria com que diversas associações surgissem provenientes da sociedade civil, com o objetivo de ensinar e preparar as crianças necessitadas, entre outras, por exemplo, a Associação Protetora da Instrução à Infância Desvalida em 1871; a Sociedade Propagadora da Instrução às Classes Operárias da Lagoa em 1872; a Associação Promotora da Instrução de Meninos e Meninas em 1874; e a Associação Promotora da Infância Desamparada em 1883.

Igualmente, apareceram as Escolas Noturnas - escolas elementares para os ingênuos, e outras escolas mantidas por entidades filantrópicas "como a Escola Central (1887), instituição que recebia crianças negras para ensinar primeiras letras e um ofício, o Asilo Nossa Senhora do Bom Conselho (1877), criado para educar e cuidar de meninas cujos pais foram vitimados pela Guerra do Paraguai" (SILVA, Rosilda, 2010, p. 41).

\section{CONCLUSÃO}

Uma das experiências escolares para a infância desvalida foi a prática estabelecida antes do período imperial, no século XVIII, na América Portuguesa, com a utilização de menores nas oficinas da Marinha. Essa prática permaneceu no país independente, sendo reorganizada na década de 1840.

Outra experiência foi a das Escolas Artífices, também em regime de internato e que igualmente preparava para ofícios. Porém, essas escolas existiram por períodos efêmeros. A

\footnotetext{
${ }^{2}$ Colégio Nossa Senhora do Amparo na Província do Grão-Pará (1860-1889). Instituição pública para a assistência e a educação de meninas desvalidas na Província do Grão Pará, no período de 1860 a 1889.
} 
instalada na capital da província do Rio Grande do Norte, por exemplo, durou apenas quatro anos, de 1858 a 1862.

Ambas as experiências eram excludentes em muitos sentidos: destinavam-se a clientela masculina, não permitiam escravos, os não vacinados, os doentes ou os que portassem alguma característica ou deficiência considerada inapta ao trabalho.

Para as meninas desvalidas, fora as escolas elementares que obrigatoriamente ensinavam as artes domésticas para o público feminino, havia alguns educandários e asilos que as formavam 'para o lar'.

O que se percebe é que estas formas escolares estavam relacionadas ao mundo do trabalho. Destinavam-se a formação de mão-de-obra para vários ofícios que se faziam necessários à sociedade brasileira recém independente, e, inclusive para o recrutamento militar. Visavam também retirar das ruas as crianças que perambulavam sem ocupação, para evitar desordens.

Todavia, apesar de possibilitarem uma profissão à infância desvalida, eram majoritariamente excludentes visto que, ao final do Império, para uma população de ao redor de 14 milhões de habitantes, menos de $2 \%$ frequentavam algum tipo de escola.

\section{REFERÊNCIAS BIBLIOGRÁFICAS}

1. AULETE, Caldas F. J. Diccionario Contemporâneo da Lingua Portugueza. Lisboa: Imprensa Nacional, 1881.

2. BRASIL. Decreto no 1.331-a, de 17 de fevereiro de 1854. Approva o Regulamento para a reforma do ensino primario e secundario do Municipio da Côrte. Coleção de Leis do Império do Brasil, Rio de Janeiro: Typographia Nacional, 1854. Disponível em: http://www2.camara .leg.br/legin/fed/decret/1824-1899/decreto-1331-a-17-fevereiro-1854-590146publicacaooriginal-115292-pe.html. Acesso em out. 2015.

3. BRASIL. Lei de 15 de outubro de 1827. Rio de Janeiro: Typographia Nacional, 1878c. Collecção das Leis do Império do Brazil de 1827.

4. BRASIL. Lei de 16 de dezembro de 1830. Manda executar o Codigo Criminal. Coleção de Leis do Império do Brasil, Rio de Janeiro: Typographia Nacional, 1830. Disponível em: http://www. planalto.gov.br/ccivil_03/leis/LIM/LIM-16-12-1830.htm . Acesso em out. 2015.

5. BRASIL. Lei no 243, de 30 de Novembro de 1841. Fixando a Despeza, e Orçando a Receita para o Exercicio do anno financeiro de 1842 - 1843. Coleção de Leis do Império do Brasil - 1841. Disponível em: http://www.camara.gov.br/legin/fed/lei/1824-1899/lei-243-30-novembro1841-561093-publicacaooriginal-84470-pl.html. Acesso em out. 2015.

6. BRASIL. Instrucções para execução, do Regulamento n. 113 de 3 de Janeiro de 1842, que deu nova organisação ás Companhias de Aprendizes Menores do Arsenal de Guerra. Disponível em: https://www.diariodasleis.com.br/legislacao/federal/202102-dando-nova-organisacaoas-companhias-de-aprendizes-menores-dos-arsenaes-de-guerra-em-conformidade-do-art39-da-lei-n-243-de-30-de-novembro-de-1841.htm. Acesso em out. 2015.

7. BRASIL. Regulamento n. 113 - de 3 de Janeiro de 1842. Dando nova organisação ás Companhias de Aprendizes Menores dos Arsenaes de Guerra. Coleção de Leis do Império do Brasil, Rio de Janeiro: Typographia Nacional, 1842. Disponível em: http://www.planalto.gov.br/ccivil_03/ 
leis/LIM/LIM-16-12-1842.htm. Acesso em out. de 2015.

8. BOTELHO, Angela Vianna; REIS, Liana Maria. Dicionário Histórico Brasil, Colônia e Império. 6ạ ed. Belo Horizonte: Autêntica, 2008.

9. CRUDO, Matilde Araki. Os Aprendizes do Arsenal de Guerra de Mato Grosso: Trabalho Infantil e Educação. Cuiabá, 1999. Tese de Doutorado, Instituto de Educação - IE -Universidade Federal de Mato Grosso - UFMT, 1999.

10. CRUDO, Matilde Araki Crudo. Resistência e Disciplina em Mato Grosso (1842-1899). In: III Congresso Luso-brasileiro de História da Educação. Escola, culturas e identidades. Coimbra, 2000. Disponível em: http://sbhe.org.br/novo/congressos/cbhe2/pdfs/Tema7/0763.pdf. Acesso em out 2015.

11. CUNHA, Luis Antonio. O Ensino de Ofícios artesanais e manufatureiros no Brasil escravocrata. - 2. Ed. São Paulo: Editora UNESP, 2005.

12. GARCIA, Daniel Melo. Desenvolvimento histórico da responsabilização criminal do menor infrator. In: Âmbito Jurídico, Rio Grande, XIV, n. 94, nov 2011. Disponível em: http://www.am bitojuridico.com.br/site/index.php?n_link=revista_artigos_leitura\&artigo_id=10594. Acesso em out 2015.

13. LIMA, Guaraciane Mendonça de. O Collégio de Educandos Artífices - 1865-1874: A Infância Desvalida da Parahyba do Norte. João Pessoa, 2008. Dissertação de Mestrado - Programa de Pós-graduação em História, do Centro de Ciências Humanas, Letras e Artes da Universidade Federal da Paraíba - UFPB, 2008.

14. SABINO, Elianne Barreto. A Assistência e a Educação de Meninas Desvalidas no Colégio Nossa Senhora do Amparo na Província do Grão-Pará (1860-1889). Belém/PA: UFPA, 2012. Dissertação apresentada ao Mestrado em Educação do Programa de Pós-Graduação em Educação do Instituto de Ciências da Educação, da Universidade Federal do Pará, 2012.

15. SCHULER, Alessandra. Infância. In: Ronaldo Vainfas (org.). Dicionário do Brasil Imperial (18221889). Rio de Janeiro: Objetiva, 2002.

16. SILVA, Robson Roberto. O cotidiano dos meninos internados no Seminário de Santana na cidade de São Paulo (1825 - 1874) FACES DA HISTÓRIA, Assis-SP, v.2, no 1, p. 202-222, jan.jun., 2015. p.207

17. SILVA, Rosilda Germano da. O Colégio de Educandos Artífices no Brasil-Império: As Raízes do Ensino Profissional para as crianças pobres em Alagoas(1854-1861). Maceió, 2010. Trabalho de Conclusão de Curso Pedagogia - Centro de Educação da Universidade Federal de Alagoas, 2010. Disponível em: http://www.cedu.ufal.br/grupopesquisa/gephecl/ocolegiode educandosartifices.pdf. Acesso em out. 2015.

18. SILVA, Wandoberto Francisco da. O destino dos filhos pobres, órfãos e enjeitados de Pernambuco: as Companhias de Aprendizes da Marinha (1847-1857). In: Anais do XXVI Simpósio Nacional de História ANPUH. São Paulo, julho 2011. Disponível em: http://www.snh2011.anpuh.org/resources/anais/14/1296683656_ARQUIVO_TrabalhodoSim posioNacionalrevisadolll.pdf. Acesso em out. 2015.

19. TAMURA, Silvio Takeshi. De Aprendizes do Arsenal de Guerra (1842-1899) a Aprendizes da Escola de Artífices (1909-1941): algumas observações sobre a educação profissional de jovens e meninos na História da Educação de Mato Grosso. Anais do VII Congresso Brasileiro de 
História da Educação, Circuitos e Fronteiras da História da Educação no Brasil. Cuiabá, 2013. Disponível em: http://sbhe.org.br/novo/congressos/cbhe7/pdf/04\%20HISTORIA\%20DA\%20 EDUCACAO\%20DAS\%20CRIANCAS\%20JOVENS\%20E\%20ADULTOS\%20NO\%20BRASIL/DE\%20A PRENDIZES\%20DO\%20ARSENAL\%20DE\%20GUERRA\%20\%281842-1899\%29.pdf. Acesso em out. 2015. 